\title{
HEALTH ATTITUDES AND BEHAVIOUR AS PREDICTORS OF SELF-RATED HEALTH \\ IN RELATION TO MORTALITY PATTERNS (17-YEAR FOLLOW-UP IN A POLISH ELDERLY POPULATION - CRACOW STUDY)
}

\author{
Beata Tobiasz-Adamczyk, Piotr Brzyski, Marek S. Kopacz
}

Department of Medical Sociology, Chair of Epidemiology and Preventive Medicine, Jagiellonian University Medical College, Cracow, Poland

\begin{abstract}
SUMMARY
The aim of this 17-year Cracow (Poland) study was to examine and identify the determinants most responsible for the relationship between self-rated health and mortality in non-institutionalized elderly people. Base-line data were collected in a simple random sample of 2,605 Cracow residents, aged 65 years and over. The vital status of all individuals under study was established by monitoring city records. Death certificates were obtained for the deceased and coded according to the underlying cause of death.

Predictors related to self-rated health, developed using the results of principal component analysis, were modelled on three indexes: individual predisposition (to disease based on family history), caring about health in the past, and attitudes toward health.

Cox multivariate analysis confirmed the significant role of self-rated health in the mortality patterns of women (HR $=1.18)$. Those who cared greatly about health in the past had a lower mortality risk than those who cared poorly $(H R=1.19)$. In men, a positive attitude towards health remained an independent predictor of mortality $(H R=1.20)$. Multivariate regression models found self-rated health to be a significant independent predictor of mortality only in women with a low level of individual predisposition (hazard ratio for self-rated health $=1.35$ ) and in those with a positive attitude towards health (hazard ratio for self-rated health $=1.16$ ).
\end{abstract}

Key words: predictors of self-rated health, overall mortality, Polish elderly

Address for correspondence: B. Tobiasz-Adamczyk, Department of Medical Sociology, Chair of Epidemiology and Preventive Medicine, JagielIonian University Medical Faculty, Kopernika 7 St., 31-034 Cracow, Poland. E-mail: mytobias@cyf-kr.edu.pl

\section{INTRODUCTION}

The elderly population of Poland (i.e., those aged 65 years and over) now make up $12.8 \%$ of the general population, approximately 4.9 million people. Compared to 3.6 million people in 1986 , this number then reached $9.5 \%$ of the general population. Demographic trends and prognoses predict a steadily growing number of older people in the general population. This demographic shift in population structure, with women making up the majority of the elderly population (62.6\%), is caused by excessive mortality trends among middle-aged men and by lower average life expectancy for men compared to women. In 1986 and 2003, at age 0 , life expectancy for women was 75.3 and 78.8 years, respectively, compared to 66.9 and 70.4 years, respectively, for men. In 1986 and 2003, at age 60, women could expect to live 19.9 and 22.2 years, respectively, compared to 15.3 and 17.2 years, respectively, for men. The average longevity of elderly women currently exceeds that of men by 5 years $(1,2)$.
The social situation of elderly people in Poland remains slightly different from that reported in some Western European countries. These differences are mostly a consequence of different individual life experiences, with such contributing factors as cultural background, socio-economic conditions, different patterns of vocational and family life, religious activity, and patterns of social integration and functioning. These differences can also be explained by macrosocial differences which exist in economic conditions, health insurance and social welfare systems, and frequency of social support.

A large body of research already covers the non-medical factors which determine mortality patterns in the elderly, such as economic conditions, role of social ties, social network and role of performance (3-12). Numerous long-term studies have focused on the validity of self-rated health as a predictor of mortality among older people. A review of over thirty community studies on self-rated health and mortality patterns showed that self-rated health appears to act as a predictor of mortality, independent from 
medical, behavioural, and psychosocial risk factors $(13,14)$. Though a relationship between self-rated health and mortality was not necessarily found in all cases, in most studies, the risk of death was higher for extremely poor health scores. This relationship has been better documented for men than for women. The results of these studies confirmed two- or even three-fold higher mortality in elderly persons of both genders who rated their health as poor (13-17).

Interpreting the role of self-rated health in mortality patterns, including the mechanisms responsible for individual perceptions of health, varied between investigators (18-24).

Numerous studies have examined the correlations which exist between self-rated health and other health indicators, such as morbidity and disability. However, over time, a shift was observed in the approach to describing the relationship between self-rated health and other health indicators. Earlier studies, which concentrated on the somatic determinants of self-rated health, suggested further investigations focus more on psychosocial factors known to impact the perception of health $(20,22,25$, 26). These factors include the expectations of the individual to the tasks imposed upon them by their environment, family, coworkers, and friends.

Still, the question remains as to what relationship exists between self-rated health in older age and health-related attitudes and behaviours at earlier stages of life. Answering this question should incorporate objective health experiences, including level of functional status and social activity (i.e., occupational and family background).

For the purposes of this study, we interpreted "perception of health" to result from a spontaneous assessment, related practices, or changes with regard to one's enduring self-concept (27). Idler and Kasl suggested self-rated health reflects a personal estimate of longevity, and knowledge of familial risk factors. These risk factors include vulnerability to specific diseases and patterns of longevity, both based on experiences of age and the mortality of parents and grandparents. Despite the general predictive power of subjective health, little more is known about it in any more specific terms (28).

\section{AIM OF THE STUDY}

The aim of this 17-year Cracow (Poland) study was to examine and identify the most important determinants responsible for the relationship between self-rated health and mortality in noninstitutionalized elderly people.

This study worked out a model which took into account the following dimensions of health-related behaviour: concern about health, willingness to seek medical care, beliefs and attitudes with respect to personal health (motivation), perceived own vulnerability, and past experience with illness. This model was based on health motivation and personal vulnerability, based on the Health Belief Model developed by Becker and Maiman (29).

\section{MATERIAL AND METHODS}

Base-line data for this study come from a socio-medical survey conducted in 1986-87. This survey was part of an epidemiologi- cal study evaluating the health status of elderly people resident in Cracow. The vital status of all individuals under study was established by monitoring city records. Death certificates were obtained for the deceased until December 31, 2003 and coded according to the underlying cause of death.

The population under study consisted of a simple random sample of noninstitutionalized persons, aged 65 and over, resident in Cracow's city centre. A randomized sample of 2,999 individuals (1,021 men and 1,978 women) was chosen from a reference group of 8,055 residents (2,529 men and 5,526 women). Not included in the study were 394 individuals (119 men and 275 women), for reasons including death, moving out of Cracow, or declining to participate. The final sample $(n=2,605)$ represents $87 \%$ of the original sample population. Of the final group, 2,054 individuals (754 men and 1,300 women) were interviewed in an outpatient clinic and 551 individuals (148 men and 403 women), who could not attend the outpatient clinic due to health reasons or other circumstances, were interviewed in their homes.

Respondents were interviewed by specially trained interviewers, who used a structured questionnaire to measure self-rated health, previous and current attitudes towards health, health and illness behaviours in the past, frequency of seeking medical help, having the will to live, and self-assessing the hierarchy of one's life values (e.g., family, work, religion, knowledge, health, and wealth). There were also questions about chronic health conditions, level of instrumental daily living, physical activity, mobility (e.g., cooking meals, walking inside and outside one's home, shopping, and doing light and heavy housework), lifestyle (e.g., smoking and physical activity), and leisure time activities (e.g., gardening, walking, and leaving the city on weekends and holidays). Socio-demographic data included the gender of the respondent, education, occupation, place of birth, structure of household, living arrangements, marital and family status, and past and present occupational activity. All base-line interviews were conducted between January 1986 and December 1987.

The model which examined predictors of health (attitudes toward health and individual predisposition) was based on the variables presented in Table 1, which contains also scoring of answers for these variables. The principal component analysis was used to select variables to create indexes measuring individual predisposition (based on family history), caring about health in the past and attitudes toward health. Index values were calculated by summing the scores obtained for these variables.

Health status assessment was based on the following indicators:

- Self-rated health was based on question: "How do you generally evaluate your health status?" Respondents chose from five possible answers, ranging from very good ( 5 points) through good (4), fair (3), bad (2) and very bad (score 1). In analyses leading to assess predictors of self-rated health, was this variable used as a binary variable, where a score of $4-5$ points was defined as good self-rated health and a score of 1-3 points was defined as poor self-rated health.

- Number of chronic conditions reflected the following diagnoses: chronic and acute respiratory diseases, asthma, hypertension, ischemic heart disease, cardiac infarction, other heart diseases, gastric and duodenal ulcer, diabetes, and rheumatoid diseases. 
Table 1. Topics, answers, and scores included in indexes of individual predisposition, caring about health, attitudes toward health, and self-rated health

\begin{tabular}{|c|c|c|}
\hline Topic & Answers & Score \\
\hline \multirow{2}{*}{$\begin{array}{l}\text { Family members are generally healthy } \\
\text { (i.e., never or rarely sick) }\end{array}$} & yes & 2 \\
\hline & no & 1 \\
\hline \multirow{4}{*}{ Longevity of family members } & over 90 yrs & 4 \\
\hline & over 80 yrs & 3 \\
\hline & over 70 yrs & 2 \\
\hline & less then 70 yrs & 1 \\
\hline \multirow{4}{*}{$\begin{array}{l}\text { Caring about health in the past } \\
\text { (self-belief) }\end{array}$} & greatly & 4 \\
\hline & average & 3 \\
\hline & rather poorly & 2 \\
\hline & poorly & 1 \\
\hline \multirow{2}{*}{ Study participant is generally healthy (i.e., never or rarely sick) } & yes & 2 \\
\hline & no & 1 \\
\hline \multirow{3}{*}{ Seeking medical attention (i.e., professional consultation) when needed } & always contacts doctor immediately & 3 \\
\hline & sometimes delays contact with doctor & 2 \\
\hline & reports to doctor only when very sick & 1 \\
\hline \multirow{3}{*}{ Lacks the will to live } & definitely not & 3 \\
\hline & rather yes & 2 \\
\hline & definitely yes & 1 \\
\hline \multirow{2}{*}{ Health is a highly valued domain } & yes & 2 \\
\hline & no & 1 \\
\hline \multirow{2}{*}{$\begin{array}{l}\text { It is better to take care of health } \\
\text { (self-belief) }\end{array}$} & yes & 2 \\
\hline & no & 1 \\
\hline \multirow{2}{*}{$\begin{array}{l}\text { Health/sickness are dependent on one's health related behaviours } \\
\text { (self-belief) }\end{array}$} & yes & 2 \\
\hline & no & 1 \\
\hline
\end{tabular}

- Level of functional activity was a sum score reflecting participation in one or more of the following activities: light household chores (1 point), preparing meals (2), shopping (3 points), and heavy housework (e.g., cleaning floors, windows) (4 point). Mobility outside the household was measured where, in the absence of an elevator, 0 points signifies no outside mobility despite living on the first floor, 1 point signifies going for one walk per week with a flat located on the first to fourth floor and 2.5 points with a flat located on the fifth floor or higher, and 4 points for taking two walks per week despite living on the fifth floor or higher.

- Physical activity was assessed by measuring fatigue brought on by mobility. Scores were summed for difficulty (if any) associated with walking at ground level and difficulty (if any) associated with climbing stairs. A lack of fatigue after walking at ground level or climbing stairs equalled 3 points. Mobility on the ground level associated with fatigue, but without the need to relax, or reporting the need to relax after climbing two or more flights of stairs equalled 2 points. Needing to relax while walking at ground level or needing to relax at each flight of stairs equalled 1 point.

Categorized variables were used to examine the relationship between indexes of individual predisposition, caring about health in the past, and attitudes toward health (i.e., health assessment and self-rated health). Univariate and multivariate logistic regression models were used to evaluate the influence of the dimensions measured in these indexes. Dimensions were adjusted for sociodemographic variables (e.g., age, place of birth), level of education, occupation, quality of living conditions (e.g., central heating, coal-burning stove, bathroom), structure of household, physical activity, smoking, number of chronic health conditions, level of functional activity, and fatigue associated with mobility.

Risk of death was calculate using univariate and multivariate Cox proportional hazard models.

Firstly, analysis describing patterns of mortality in the elderly assessed the role of self-rated health adjusted for demographic variables (e.g., age, place of birth), level of education, occupation, quality of living conditions, structure of household, physical activity, number of chronic health conditions, level of functional activity, fatigue associated with mobility, smoking, and the indexes of individual predisposition to disease, caring about health in the past, and attitudes toward health, respectively.

Secondly, analysis was performed to examine the role of these indexes as factors modifying the relationship between self-rated health and mortality patterns. Mortality risk in relation to selfrated health was conducted separately in participants with high vs. low individual predisposition, caring greatly vs. little about health in the past, and in groups with positive vs. negative attitudes toward health. Models were subsequently adjusted for those variables used in the first step.

Analysis was performed using SPSS 12 PL for Windows statistical package. 


\section{RESULTS}

\section{Base-line Characteristics of the Study Population}

Demographic and social characteristics of the 2,605 participants showed that, at the base-line study performed in 1986-87, there were $902(34.6 \%)$ men and 1,703 (65.4\%) women, mean age 72.0 years. More women $(50.1 \%)$ than men $(21.0 \%)$ reported the lowest form of education (i.e., primary school or no formal education). Low occupational status was confirmed by $48.2 \%$ men and $58.3 \%$ women. The average occupational history for men was 36.2 years and 25.5 years for women. Living alone was reported by $35.9 \%$ of women and $15.5 \%$ of men. Widows dominated in the female group (50.4\%), while most men remained married (74.3\%). Having children was reported by $81.6 \%$ of men and $70.0 \%$ of women.

More women (23.2\%) than men (18.9\%) self-rated their present health as fair or bad. Gender-related differences were observed for hypertension and myocardial infarction as well as mean number of chronic health conditions (males 1.94 vs. females 2.31). More men $(14.7 \%)$ than women (8.5\%) confirmed a low level of functional activity. Fatigue brought on by physical activity was more frequently encountered in women (36.5\%) than in men (23.1\%). Lacking the will to live was reported by $4.7 \%$ of women and $3.0 \%$ of men. Despite retirement, more men $(15.2 \%)$ than women (4.8\%) continued to work.

\section{Characteristics of the Developed Indexes}

Based on the results of principal component analysis (Table 2) of variables presented in Table 1, three indexes were created:

1. Index of individual predisposition (based on family history), which was sum of scores for variables highly loading the second component: "family members are generally healthy" and "longevity of family members"; possible score of 2-6: in further analysis scores 5-6 points were indicative of high predisposition, 2-4 points reflected low predisposition.

2. Index of caring about health in the past, which was a sum of scores for variables highly loading the first component: "caring about health in the past", "study participant is generally

Table 2. Principal component analysis with varimax rotation for index variables

\begin{tabular}{|l|c|c|c|c|}
\hline \multirow{2}{*}{} & \multicolumn{4}{|c|}{ Component } \\
\cline { 2 - 5 } & 1 & 2 & 3 & 4 \\
\hline Variance explained by component: & $27 \%$ & $16 \%$ & $13 \%$ & $11 \%$ \\
\hline Seeking medical attention when needed & 0.79 & 0.00 & -0.01 & -0.12 \\
\hline Study participant is generally healthy & 0.73 & 0.09 & 0.15 & 0.06 \\
\hline Caring about health in the past & 0.77 & 0.13 & -0.05 & 0.09 \\
\hline Lack of will to live & -0.68 & 0.02 & -0.11 & -0.08 \\
\hline Family members are generally healthy & 0.01 & 0.88 & 0.04 & -0.03 \\
\hline Longevity of family members & 0.12 & 0.86 & 0.01 & 0.07 \\
\hline It is better to take care of health & -0.02 & 0.03 & 0.79 & 0.05 \\
\hline $\begin{array}{l}\text { Health/sickness are dependent on one's } \\
\text { health related behaviours }\end{array}$ & 0.14 & 0.02 & 0.74 & -0.05 \\
\hline Health is a highly valued domain & 0.07 & 0.03 & 0.00 & 0.99 \\
\hline
\end{tabular}

Values in bold are the highest loadings of the variable. healthy" and "seeking medical attention when needed"; possible score of 3-9: in further analysis scores 6-9 points was defined as caring greatly about health in the past, $3-5$ points was defined as caring little about health in the past. Variable "will to live", in spite of its highest loading on this component, but because of its meaning, was included into index of attitudes toward health.

3. Index of attitudes toward health, which was a sum of scores for variables highly loading the third and fourth components: "health is a highly valued domain", "it is better to take care of health" and "health/sickness are dependent on one's health related behaviours". Variable "will to live", because of its meaning, was also included into this index; possible score of 3-9: in further analysis scores 7-9 points signified positive health-related attitudes, 3-6 points reflected negative healthrelated attitudes.

High individual predisposition characterized $49.2 \%$ of men and $45.8 \%$ of women. Of the men, $54.2 \%$ reported caring greatly about their health in the past, compared to $49.9 \%$ of women. Positive attitudes towards health were confirmed by $38.6 \%$ of men and $29.6 \%$ of women.

In the index of individual predisposition, women and men more frequently self-rated their health as poor when their individual predisposition was low (high family history for illness). This difference was not statistically significant. In the index for caring about health in the past, intragroup comparison found those who cared greatly about their health were six-time more likely to report poor self-rated health, compared to those who cared moderately. In the index of attitudes toward health, poor self-rated health was more frequently reported by respondents with positive attitudes towards health (Table 3).

Multivariate logistic regression models showed that low individual predisposition significantly increased the risk of poor self-rated health in males, but caring greatly about health in the past also increased the risk of poor self-rated health.

These results suggest that caring about health in the past and attitudes toward health were influenced by objective health status. After excluding care about health index from the model, individual predisposition based on family history remained the most significant predictor of poor self-rated health (Table 4).

Other variables included into the analysis also significantly influenced the risk of poor self-rated health. These variables included age, place of residence, structure of household, level of education, occupation, occupational exposure to industrial agents, smoking, tiredness associated with physical activity, number of chronic conditions, living arrangements, and health behaviours related to physical activity.

\section{Mortality Patterns}

During the 17-year follow-up period, 676 (74.9\%) men and $1,092(64.1 \%)$ women died. This gives a total mortality of 1,768 $(67.9 \%)$ individuals from the sample population. Mortality risk was related to age and gender. Figure 1 presents survival curves for men and women, drawn for respondents with a mean age of 72 years. Our findings support previous knowledge on genderrelated differences in survival rates.

Multivariate Cox analysis confirmed the significant role of self-rated health only in the mortality patterns of women. A higher risk of mortality was found in those who cared little about their 
Table 3. Relationship between self-rated health and the indexes of individual predisposition, caring about health and attitudes toward health

\begin{tabular}{|c|c|c|c|c|c|c|}
\hline \multirow{3}{*}{ Index } & & \multicolumn{4}{|c|}{ Self-rated health } & \multirow{3}{*}{ OR } \\
\hline & & \multicolumn{2}{|c|}{ good } & \multicolumn{2}{|c|}{ bad } & \\
\hline & & $\mathrm{n}$ & $\%$ & $\mathrm{n}$ & $\%$ & \\
\hline \multicolumn{7}{|l|}{ Men } \\
\hline \multirow{2}{*}{ Individual predisposition } & high & 368 & 83.1 & 75 & 16.9 & 1 \\
\hline & low & 341 & 79.1 & 90 & 20.9 & 1.30 \\
\hline \multirow{2}{*}{ Caring about health } & high & 343 & 70.3 & 145 & 29.7 & 1 \\
\hline & low & 384 & 94.1 & 24 & 5.9 & $0.15^{\star}$ \\
\hline \multirow{2}{*}{ Attitudes toward health } & positive & 271 & 77.9 & 77 & 22.1 & 1 \\
\hline & negative & 447 & 84.7 & 81 & 15.3 & $0.64^{*}$ \\
\hline \multicolumn{7}{|l|}{ Women } \\
\hline \multirow{2}{*}{ Individual predisposition } & high & 609 & 78.3 & 169 & 21.7 & 1 \\
\hline & low & 670 & 76.2 & 209 & 23.8 & 2.04 \\
\hline \multirow{2}{*}{ Caring about health } & high & 513 & 60.5 & 335 & 39.5 & 1 \\
\hline & low & 787 & 93.1 & 58 & 6.9 & $0.11^{*}$ \\
\hline \multirow{2}{*}{ Attitudes toward health } & positive & 355 & 70.6 & 148 & 29.4 & 1 \\
\hline & negative & 922 & 81.6 & 208 & 18.4 & $0.54^{\star}$ \\
\hline
\end{tabular}

$* p<0.05$

Table 4. Determinants of low self-rated health, based on multivariate logistic regression models

\begin{tabular}{|l|c|c|c|c|c|c|}
\hline & \multicolumn{3}{|c|}{ Men } & \multicolumn{3}{c|}{ Women } \\
\hline & OR & \multicolumn{2}{|c|}{$95 \% \mathrm{Cl}$} & OR & \multicolumn{2}{c|}{$95 \% \mathrm{Cl}$} \\
\hline $\begin{array}{l}\text { High individual predisposition } \\
\text { (ref.) }\end{array}$ & 1 & & & 1 & & \\
\hline Low individual predisposition & 1.67 & 1.06 & 2.63 & 1.10 & 0.79 & 1.54 \\
\hline $\begin{array}{l}\text { Positive attitudes toward health } \\
\text { (ref.) }\end{array}$ & 1 & & & 1 & & \\
\hline $\begin{array}{l}\text { Negative attitudes toward } \\
\text { health }\end{array}$ & 0.68 & 0.43 & 1.08 & 0.78 & 0.55 & 1.10 \\
\hline
\end{tabular}

Models adjusted for: age, place of birth. living arrangements, education level, occupational status, exposure to unhealthy agents, fatigue caused by physical activity level of functional activity, number of chronic conditions, living conditions, smoking, and physical activity.

$95 \% \mathrm{Cl}$ is a $95 \%$ confidence interval for $\mathrm{HR}$.

Values in bold are statistically significant.

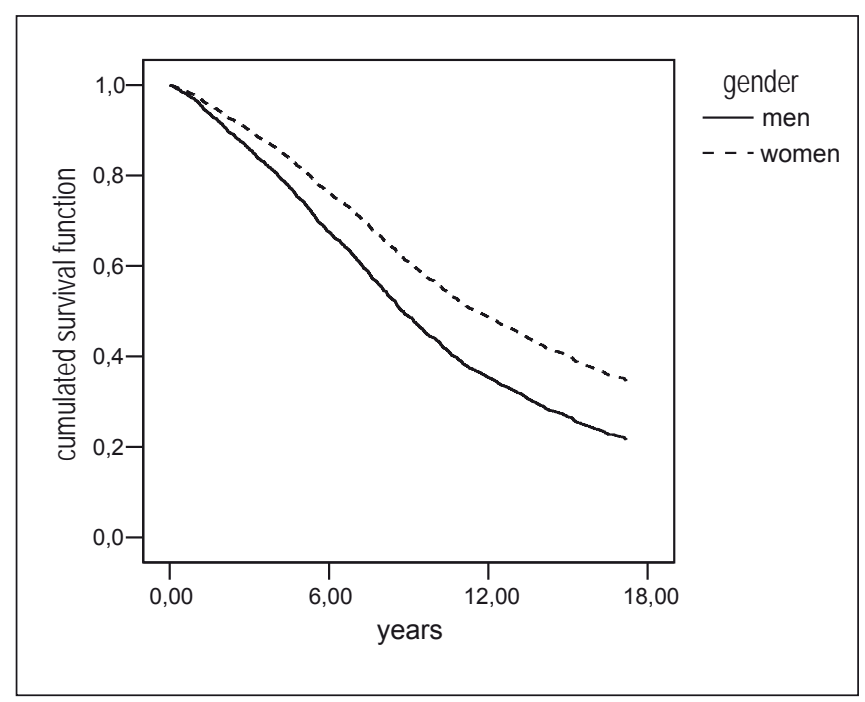

Fig. 1. Cumulated survival function for men and women.

in terms of the psychological processes which underlie global assessment of health status. This has resulted in various attempts to establish a relationship between self-rated health and the external criteria of mortality. However, little is known about the subjective dimensions of health. At present, knowledge of the processes underlying the subjective evaluation of general health is very limited. Investigators can only speculate about the introspective processes respondents use to construct their evaluation $(23,30)$.

This study has attempted to explore the mechanisms underlying the assessment of subjective health in older age, relating these mechanisms to self-reported health beliefs, health attitudes, and health-related behaviours characteristics for earlier stages of life. The results show an inverse relationship between the analyzed variables, which describe health-related attitudes and behaviours 
Table 5. Mortality risk, based on multivariate Cox proportional hazard models

\begin{tabular}{|l|c|c|c|c|c|c|}
\hline & \multicolumn{3}{|c|}{ Men } & \multicolumn{3}{c|}{ Women } \\
\hline & HR & \multicolumn{2}{|c|}{$95 \% \mathrm{Cl}$} & HR & \multicolumn{2}{c|}{$95 \% \mathrm{Cl}$} \\
\hline Self-rated health" & 1.05 & 0.90 & 1.23 & 1.18 & 1.03 & 1.35 \\
\hline High individual predisposition (ref.) & 1 & & & 1 & & \\
\hline Low individual predisposition & 0.99 & 0.84 & 1.18 & 0.91 & 0.79 & 1.05 \\
\hline Cared greatly about health in the past (ref.) & 1 & & & 1 & & 1.01 \\
\hline Cared little about health in the past & 0.89 & 0.72 & 1.09 & 1.19 & 1.43 \\
\hline Positive attitudes toward health (ref.) & 1 & & & 1 & & \\
\hline Negative attitudes toward health & 1.20 & 1.01 & 1.45 & 1.10 & 0.93 & 1.30 \\
\hline
\end{tabular}

\# - presented as a continuous variable: lower values reflect very good self-rated health. higher values reflect very poor self-rated health

Models adjusted for age. place of birth, living arrangements, education, occupational status, exposure to unhealthy agents, fatigue caused by physical activity, level of functional activity, number of chronic health conditions, living conditions, smoking and physical activity.

$95 \% \mathrm{Cl}$ is a $95 \%$ confidence interval for $\mathrm{HR}$.

Values in bold are statistically significant.

Table 6. Relating self-rated health to mortality risk in groups of respondents characterized by particular indexes, based on multivariate Cox proportional hazard models

\begin{tabular}{|l|c|c|c|c|c|c|}
\hline Group & \multicolumn{3}{|c|}{ Men } & \multicolumn{4}{c|}{ Women } \\
\hline & HR & \multicolumn{2}{|c|}{$95 \% \mathrm{Cl}$} & HR & \multicolumn{2}{c|}{$95 \% \mathrm{Cl}$} \\
\hline High individual predisposition 1) & 0.98 & 0.83 & 1.16 & 1.06 & 0.91 & 1.23 \\
\hline Low individual predisposition 1) & 1.03 & 0.73 & 1.45 & 1.35 & 1.03 & 1.75 \\
\hline Cared greatly about health in the past 2) & 1.02 & 0.88 & 1.19 & 1.14 & 0.99 & 1.28 \\
\hline Cared little about health in the past 2) & 1.92 & 0.76 & 5.00 & 1.59 & 0.52 & 4.76 \\
\hline Positive attitudes toward health 3) & 0.99 & 0.83 & 1.16 & 1.16 & 1.01 & 1.35 \\
\hline Negative attitudes toward health 3) & 1.04 & 0.66 & 1.64 & 1.04 & 0.77 & 1.39 \\
\hline
\end{tabular}

Self-rated health is presented as a continuous variable: lower values reflect very good self-rated health, higher values reflect very poor self-rated health.

Models adjusted for age, place of birth, living arrangements, education, occupational status, exposure to unhealthy agents, fatigue caused by physical activity, level of functional activity, number of chronic health conditions, living conditions, smoking and physical activity, individual predisposition (except groups 1), care about health in the past (except groups 2) and positive attitudes toward health (except groups 3 ).

$95 \% \mathrm{Cl}$ is a $95 \%$ confidence interval for $\mathrm{HR}$.

Values in bold are statistically significant.

at earlier stages of life, and self-rated health, as reported during the base-line interview.

The longevity of family members and how one perceives their predisposition to illness based on family history appears to play an important role in health-related attitudes and behaviours. These findings corresponded with Idler's suggestions that self-assessment of health reflects a personal estimate of familial risk factors $(14,32)$. The main question associated with the analyzed variables is whether the relationship between self-rated health and healthrelated self-concept is one of temporal stability in assessment or a dynamic trajectory of judgment (27).

One advantage of this study is the relatively long, 17-year, monitoring period of overall mortality patterns. This period is longer than stated in other studies, where follow-up ranged from 9-13 years, one exception being a study covering a 28 -year monitoring period $(14,31)$. The mortality rate $(67.9 \%)$ observed in this study was relatively high and gender-related differences in mortality patterns could also be observed.

Contrary to expectations and the findings of other authors, these results did not confirm the role of self-rated health as an independent predictor of mortality in men, although a significant relationship existed for women. While most studies show that self-rated health is a strong predictor of mortality in both genders, some studies confirm the significant role of self-rated health as a predictor of mortality only in women.

Though self-rated health in men was not a significant predictor of mortality, it is important to mention that the index of positive attitudes toward health was found to be an independent predictor of mortality in this group. In women, caring greatly about health in the past was an important predictor of lower mortality risk. Self-rated health is a significant predictor of mortality in women with high individual predisposition to illness and in those with previously positive attitudes towards health. Contrary to expectations, caring little about health in the past and poor attitudes towards health were neither directly nor indirectly associated with poor self-rated health in men. Data coming from a 13-year follow-up study in a sample of Cracow residents, aged 19-70 years, confirmed a significant relationship between poor self-rated health and mortality in men. This study, however, focused more on younger age groups (33).

Gender-related differences in the perception of health status bring about the question whether men and women use the same criteria in assessing their health and whether their reference-notion of health is similar (25). As has already been established, self- 
rated health is a significant intervening variable in the relationship between objective health determinants and life satisfaction $(19,22,34)$.

It is also important to underline the significant influence on self-rated health of the longevity of family members and individual predisposition to illness. Family history appears to be an important and independent predictor of health perception, directly and indirectly influencing attitudes towards health and health-related behaviours during different stages of life. As an outcome, it significantly determines mortality patterns in the elderly.

\section{REFERENCES}

1. Central Statistical Office. Statistical yearbook of the Republic of Poland. Warsaw: Central Statistical Office; 1987.

2. Central Statistical Office. Statistical yearbook of the Republic of Poland. Warsaw: Central Statistical Office; 2004.

3. Koskinen S, Martelin T. Why are socioeconomic mortality differences smaller among women than among men? Soc Sci Med. 1994 May;38(10):1385-96.

4. Malmström M, Johansson SE, Sundquist J. A hierarchical analysis of long-term illness and mortality in socially deprived areas. Soc Sci Med. 2001 Aug;53(3):265-75.

5. Uitenbroek DG, Verhoeff AP. Life expectancy and mortality differences between migrant groups living in Amsterdam, The Netherlands. Soc Sci Med. 2002 May;54(9):1379-88.

6. Fukuda Y, Nakamura K, Takano T. Municipal socioeconomic status and mortality in Japan: sex and age differences, and trends in 1973-1998. Soc Sci Med. 2004 Dec;59(12):2435-45.

7. Blazer DG. Social support and mortality in an elderly community population. Am J Epidemiol. 1982 May;115(5):684-94.

8. Seeman TE, Kaplan GA, Knudsen L, Cohen R, Guralnik J. Social network ties and mortality among the elderly in the Alameda County Study. Am J Epidemiol. 1987 Oct;126(4):714-23.

9. Hibbard JH, Pope CR. The quality of social roles as predictors of morbidity and mortality. Soc Sci Med. 1993 Feb;36(3):217-25.

10. Yasuda N, Zimmerman SI, Hawkes W, Fredman L, Hebel JR, Magaziner J. Relation of social network characteristics to 5-year mortality among young-old versus old-old white women in an urban community. Am J Epidemiol. 1997 Mar 15;145(6):516-23.

11. Cerhan JR, Wallace RB. Change in social ties and subsequent mortality in rural elders. Epidemiology. 1997 Sep;8(5):475-81

12. Kennelly B, O'Shea E, Garvey E. Social capital, life expectancy and mortality: a cross-national examination. Soc Sci Med. 2003 Jun;56(12):236777.

13. Idler EL, Kasl SV, Lemke JH. Self-evaluated health and mortality among the elderly in New Haven, Connecticut, and Iowa and Washington counties, Iowa, 1982-1986. Am J Epidemiol. 1990 Jan;131(1):91-103.

14. Idler EL, Benyamini Y. Self-rated health and mortality: a review of twenty-seven community studies. J Health Soc Behav. 1997 Mar;38(1):2137.
15. Kaplan G, Barell V, Lusky A. Subjective state of health and survival in elderly adults. J Gerontol. 1988 Jul;43(4):S114-20.

16. Mossey JM, Shapiro E. Self-rated health: a predictor of mortality among the elderly. Am J Public Health. 1982 Aug;72(8):800-8.

17. Yu ES, Kean YM, Slymen DJ, Liu WT, Zhang M, Katzman R. Self-perceived health and 5-year mortality risks among the elderly in Shanghai, China. Am J Epidemiol. 1998 May 1;147(9):880-90.

18. Jylhä M, Leskinen E, Alanen E, Leskinen AL, Heikkinen E. Self-rated health and associated factors among men in different ages. J Gerontol. 1986 Nov;41(6):710-7.

19. Fylkesnes K, Frrrde OH. Determinants and dimensions involved in selfevaluation of health. Soc Sci Med. 1992 Aug;35(3):271-9.

20. Krause NM, Jay GM. What do global self-rated health items measure? Med Care. 1994 Sep;32(9):930-42.

21. Kempen GI, Miedema I, van den Bos GA, Ormel J. Relationship of domain-specific measures of health to perceived overall health among older subjects. J Clin Epidemiol. 1998 Jan;51(1):11-8.

22. Borg V, Kristensen TS. Social class and self-rated health: can the gradient be explained by differences in life style or work environment? Soc Sci Med. 2000 Oct;51(7):1019-30.

23. Baron-Epel O, Kaplan G. General subjective health status or age-related subjective health status: does it make a difference? Soc Sci Med. 2001 Nov;53(10):1373-81.

24. Bryant LL, Corbertt KK, Kutner JS. In their own words: a model of healthy ageing. Soc Sci Med. 2001 Oct;53(7):927-41.

25. Manderbacka $\mathrm{K}$, Kåreholt I, Martikainen $\mathrm{P}$, Lundberg $\mathrm{O}$. The effect of point of reference on the association between self-rated health and mortality. Soc Sci Med. 2003 Apr;56(7):1447-52.

26. Krause N. Satisfaction with social support and self-rated health in older adults. Gerontologist. 1987 Jun;27(3):301-8.

27. Bailis DS, Segall A, Chipperfield JG. Two views of self-rated general health status. Soc Sci Med. 2003 Jan;56(2):203-17.

28. Benjamins MR, Hummer RA, Eberstein IW, Nam CB. Self-reported health and adult mortality risk: an analysis of cause-specific mortality. Soc Sci Med. 2004 Sep;59(6):1297-306.

29. Siegrist J. Models of health behaviour. Eur Heart J. 1988 Jun;9(6):70914.

30. Benyamini Y, Leventhal EA, Leventhal H. Elderly people's ratings of the importance of health-related factors to their self-assessments of health Soc Sci Med. 2003 Apr;56(8):1661-7.

31. Benyamini Y, Idler EL. Community studies reporting associations between self-rated health and mortality: additional studies, 1995 to 1998 . Res Ageing. 1999;21(3):392-401.

32. Benyamini Y, Leventhal EA, Leventhal H. Self-assessment of health: what do people know that predicts their mortality? Res Ageing. 1999;21:477500.

33. Krzyżanowski M, Wysocki M. The relation of thirteen-year mortality to ventilatory impairment and other respiratory symptoms: the Cracow study. Int J Epidemiol. 1986 Mar;15(1):56-64.

34. Manderbacka K, Lundberg O. Examining points of reference of selfrated health among Swedish oldest old. Arch Gerontol Geriatr. 1996 Jul-Aug;23(1):47-60.

Received November 12, 2007 Accepted in revised form February 20, 2008 